\title{
Upper gastrointestinal promotility drugs: not all uniform?
}

\author{
Rita Brun • Braden Kuo
}

The pathophysiology of functional gastrointestinal (GI) disorders has been under broad investigation in the past two decades; dysmotility remains one of the main focuses of the research. Numerous studies have documented abnormal gastroduodenal motility in patients with functional dyspepsia, irritable bowel syndrome, and other functional GI disorders. In functional dyspepsia, the abnormalities range from delayed to accelerated gastric emptying, abnormal antral and fundic contractions, and disordered accommodation in the fundus and antrum. Some of the functional GI symptoms may be explained by disturbed motility both during and after the meal. Less is known about small bowel dysmotility. Alterations in small bowel transit time, proximal small bowel accommodation, and abnormal contractions may play a role in pathophysiology of symptoms of the functional disorders. Currently, we have witnessed rapidly accumulating knowledge about the functional characteristics of GI tract motility. Some new tools are available such as a wireless motility capsule ${ }^{1}$ or impedance $\mathrm{pH}$ test. These tests can give additional information about the relationships between GI transit and contractility as measured by manometry. But antroduodenal manometry, though uncommonly performed, still provide fascinating insights into upper GI motility.

Using promotility agents to treat functional GI disorders is very attractive, given that they may target some of the underlining pathophysiologic mechanisms. Unfortunately, most of them are only modestly effective. This may be due to the fact that normal gut motility is a complex interaction between multiple neurotransmitters, while available drugs

\footnotetext{
R. Brun · B. Kuo,

GI Unit, Massachusetts General Hospital,

Harvard Medical School,

Boston, MA, USA

B. Kuo $(\square)$

e-mail: bkuo@partners.org

(C) Indian Society of Gastroenterology 2009
}

usually target only one neurotransmitter or receptor involved in the maintaining of normal GI motility function.

The need for effective promotility agent both for stomach and small bowel is desperate. Several classes of pharmacological agents exist, with different amounts of evidence for their efficacy: D2 antagonists as methoclopramide and domperidone, motilin agonist erythromycin, serotonin receptor antagonists such as cisapride, alosetron, ${ }^{2}$ and tegaserod, D2 antagonist and acetylcholinesterase inhibitor itopride; however, many of them have been removed from the market due to safety issues.

Tegaserod is a 5-HT4 partial agonist and 5-HT2b antagonist. ${ }^{3}$ Tegaserod $6 \mathrm{mg}$ bid was first approved by the US FDA for constipation in female patients with irritable bowel syndrome, and has shown efficacy in the treatment of abdominal pain and discomfort. ${ }^{4}$ In general, it is welltolerated except for the adverse effect of transient diarrhea in about $10 \%$ of recipients. ${ }^{5}$ However, in 2007 Tegaserod was withdrawn from market because of increased incidence of cardiac ischemic events. ${ }^{6}$

The effects of tegaserod on different parts of the GI tract have been studied. Tegaserod accelerates gastric emptying and enhance gastric accommodation. ${ }^{7}$ In functional dyspepsia studies, improvement of symptoms and gastric emptying were shown with tegaserod $6 \mathrm{mg}$ bid. ${ }^{8}$ Tegaserod appears to have an effect on visceral afferent function, reducing pain and discomfort associated with noxious distensions of the colorectum in animals, and increasing motility in the dog as well as accelerating transit in the small bowel and colon. ${ }^{5}$ But, it does not change esophageal motility and gastro-esophageal reflux parameters in healthy volunteers. ${ }^{9}$

One study examined the GI transit by scintigraphy with and without tegaserod, and revealed that the drug significantly accelerated gastric emptying, small bowel, and colonic transit times and the most prominent prokinetic effects were observed in the upper GI tract-stomach and small intestine. ${ }^{10}$

Erythromycin stimulates smooth muscle motilin receptors. It was introduced clinically in the 1990 s as an agent to 
increase motility by Janssens et al, ${ }^{12}$ who demonstrated that the acute administration of this macrolide antibiotic accelerated gastric emptying of solids and increased antral contractions in patients with diabetes, some of whom also had evidence of gastric stasis. It has been found to be effective in diabetic gastroparesis at the dosage of 500 qid $\mathrm{PO}^{13}$ and $200 \mathrm{mg}$ tid IV or PO. ${ }^{12}$ However, its effect tends to decrease with chronic use. ${ }^{14}$ In the acute setting, it has been used in upper GI bleeding to empty the stomach prior to endoscopy, and its action appears to be fast and effective. ${ }^{15}$ Less is known about the effects of erythromycin in the small intestine. Attempts to use erythromycin for adynamic ileus following abdominal surgery in adults were unsuccessful, and the meta-analysis of those studies showed absence of effect. ${ }^{16}$

In this issue of the Journal, Nasr et $a l^{17}$ report the results of an open label, prospective, non-crossover study which compared the effects of tegaserod and erythromycin on upper gut motility. They performed antroduodenojejunal manometry on 22 patients with different functional upper GI symptoms suggestive of dysmotility, as abdominal pain, bloating, vomiting, and diarrhea, at baseline and after administration of the drugs. The manometric data were analyzed for 90 minutes after erythromycin and for 180 minutes following tegaserod. Increased motor activity $(\mathrm{p}<0.05)$ in antrum, duodenum, and jejunum with both drugs when compared to baseline period was demonstrated.

In this study, the motor response with tegaserod was higher $(\mathrm{p}<0.05)$ in jejunum and occurred within $1-3$ hours, while 'fed-response' pattern was seen in antrum, duodenum, and jejunum. Erythromycin induced higher motor response in antrum $(\mathrm{p}<0.05)$ and occurred earlier, within 30 minutes, with large amplitude $(>100 \mathrm{mmHg})$ antral contractions at three cycles per minute. Phase III MMCs occurred in 55\% patients following tegaserod and $36 \%$ patients after erythromycin $(\mathrm{p}>0.05)$.

The authors conclude that both the drugs increase upper gut motility and induce MMCs, but cause a different response. Tegaserod produces a more sustained prokinetics effect in the duodenum/jejunum, whereas erythromycin predominantly increases antral motor activity.

The study of Nasr et $a l^{17}$ provides an interesting and important insight into the specific differentiation of prokinetic effect of various pharmacological agents on the upper GI tract. These new data about the effects of erythromycin and tegaserod on small bowel contribute to the growing knowledge about the motility physiology of the GI tract.

There are a few other studies comparing these promotility agents which help support these findings. Pimental et $a l,{ }^{18}$ compared the therapeutic effect of low dose erythromycin versus tegaserod. They chose those agents based on the fact that tegaserod is effective in reducing of abdominal pain and bloating, and facilitates bowel transit in IBS, while erythromycin, as a motilin agonist, is known to increase the frequency of phase III interdigestive motility. The study demonstrated that tegaserod was more effective in prevention of the recurrence of IBS symptoms after antibiotic treatment compared to erythromycin or no prevention. ${ }^{18}$

However, directly comparing the physiologic effects of prokinetics in humans is otherwise lacking. An in vitro study by Jarvie et al compared the gastric prokinetic activities of rabbit motilin, erythromycin, and tegaserod. Gastric prokinetic-like activity was assessed by measuring the ability to facilitate cholinergically mediated contractions evoked by electrical field stimulation in rabbit isolated stomach. The differences in the characteristics of evoked contractions after the application of each drug were shown. The maximal response achieved with erythromycin was greater than that with tegaserod. Responses to rabbit motilin faded rapidly whereas those to erythromycin and tegaserod were maintained longer. ${ }^{11}$

The study of Nasr et $a l^{17}$ is the first study highlighting the important differences of the physiologic effect of erythromycin and tegaserod in humans in the upper GI tract, but there are several limitations. One, as the authors mentioned, is the relatively small and heterogeneous patient group with different baseline symptoms and potentially different underlining abnormalities, which may also influence their response to the medications. A shorter period of time that manometric data were analyzed after erythromycin may explain fewer MMCs that were seen with erythromycin. A deficiency of migrating motor complexes has been previously reported in irritable bowel syndrome patients. ${ }^{19}$ Finding more MMCs in upper GI tract after tegaserod by the present study emphasizes the potentially important effect of tegaserod on the small bowel. This observation could be an explanation of the effectiveness of tegaserod for IBS prevention, demonstrated by Pimental et al..$^{18}$

Another interesting point is the dosage of the study drugs. Low dose erythromycin was used and the dosage of tegaserod was much higher than clinically accepted amounts. Low dose erythromycin was shown previously to be effective in stomach at inducing motility activity and has probably less clinical side effects. It is unclear whether the higher dose of tegaserod has any advantage over the regular dose of $2-6 \mathrm{mg}$. The study adds the information to the present growing data about pharmacological agents that affect GI motility, with meaningful insight into the small bowel. Tegaserod is not available in the US market, but in the future a medication with similar serotonergic properties may be developed and the present study helps understand better the pharmaco-physiologic characteristics of the class compound compared to macrolide-motilin agents. Combination of different classes of promotility agents which may affect various regions of the upper GI tract differentially could be beneficial for challenging patients with motility disorders, reflecting the complex underlining pathophysiology. 


\section{References}

1. Kuo B, McCallum RW, Koch KL, et al. Comparison of gastric emptying of a nondigestible capsule to a radiolabelled meal in healthy and gastroparetic subjects. Aliment Pharmacol Ther 2008;27:186-96.

2. Kuo B, Camilleri M, Burton D, et al. Effects of 5-HT(3) antagonism on postprandial gastric volume and symptoms in humans. Aliment Pharmacol Ther 2002;16:225-33.

3. De Maeyer, JH, Lefebvre RA, Schuurkes JA. 5-HT4 receptor agonists: similar but not the same. Neurogastroenterol Motil 2008;20:99-112.

4. Tack J, Müller-Lissner S, Bytzer P, et al. A randomised controlled trial assessing the efficacy and safety of repeated tegaserod therapy in women with irritable bowel syndrome with constipation. Gut 2005;54:1707-13.

5. Camilleri, M. Review article: tegaserod. Aliment Pharmacol Ther 2001;15:277-89.

6. Schiller, LR, Johnson DA. Balancing drug risk and benefit: toward refining the process of FDA decisions affecting patient care. Am J Gastroenterol 2008;103:815-9.

7. Tack J, Vos R, Janssens J, Salter J, Jauffret S, Vandeplassche G. Influence of tegaserod on proximal gastric tone and on the perception of gastric distension. Aliment Pharmacol Ther 2003;18:1031-7.

8. Vakil N, Laine L, Talley NJ, et al. Tegaserod treatment for dysmotility-like functional dyspepsia: results of two randomized, controlled trials. Am J Gastroenterol 2008; 103:1906-19.

9. Tutuian R, Mainie I, Allan R, et al. Effects of a 5-HT(4) receptor agonist on oesophageal function and gastrooesophageal reflux: studies using combined impedancemanometry and combined impedance-pH. Aliment Pharmacol Ther 2006;24:155-62.

10. Degen L, Petrig C, Studer D, Schroller S, Beglinger C. Effect of tegaserod on gut transit in male and female subjects. Neurogastroenterol Motil 2005;17:821-6.
11. Jarvie EM, North Laidler VJ, Corcoran S, Bassil A, Sanger GJ. Differences between the abilities of tegaserod and motilin receptor agonists to stimulate gastric motility in vitro. Br J Pharmacol 2007;150:455-62.

12. Janssens J, Peeters TL, Vantrappen G, et al. Improvement of gastric emptying in diabetic gastroparesis by erythromycin. Preliminary studies. N Engl J Med 1990;322: 1028-31.

13. Richards RD, Davenport K, McCallum RW. The treatment of idiopathic and diabetic gastroparesis with acute intravenous and chronic oral erythromycin. Am J Gastroenterol 1993;88:203-7.

14. Camilleri M. Gastrointestinal problems in diabetes. Endocrinol Metab Clin North Am 1996;25:361-78.

15. Carbonell N, Pauwels A, Serfaty L, Boelle PY, Becquemont L, Poupon R. Erythromycin infusion prior to endoscopy for acute upper gastrointestinal bleeding: a randomized, controlled, double-blind trial. Am J Gastroenterol 2006;101:1211-5.

16. Traut U, Brügger L, Kunz R, et al. Systemic prokinetic pharmacologic treatment for postoperative adynamic ileus following abdominal surgery in adults. Cochrane Database Syst Rev 2008;1:CD004930.

17. Nasr I, Rao SSC, Attaluri A, Hashmi SMA, Summers R. Effects of tegaserod and erythromycin in upper gut dysmotility: a comparative study. Indian $J$ Gastroenterol 2009;28:136-42.

18. Pimentel M, Morales W, Lezcano S, Dai S-C, Low $\mathrm{K}$, Yang J. Low-dose nocturnal tegaserod or erythromycin delays symptom recurrence after treatment of irritable bowel syndrome based on presumed bacterial overgrowth. Gastroenterol Hepatol 2009;5: 435-42.

19. Pimentel M, Soffer EE, Chow EJ, Kong Y, Lin HC. Lower frequency of MMC is found in IBS subjects with abnormal lactulose breath test, suggesting bacterial overgrowth. Dig Dis Sci 2002;47:2639-43.

\section{Indian Journal of Gastroenterology J Mitra Memorial Award}

\section{The Indian Journal of Gastroenterology bestows this award for the best original scientific contribution published in the Journal during the year}

This award carries a prize of Rs 20000 , and will be given to the department(s) submitting the selected paper. The paper will be selected by a scientific committee appointed by the Editor, from among all the Original Articles published in the Journal during the year. In the event of a tie, the award will be distributed equally. Terms for eligibilty will apply.

The award has been made possible by a generous endowment from M/s J Mitra and Co Ltd, New Delhi. 